\title{
BMJ Open Impact of rapid ultrafiltration rate on changes in the echocardiographic left atrial volume index in patients undergoing haemodialysis: a longitudinal observational study
}

\author{
Jwa-Kyung Kim, ${ }^{1,2}$ Young Rim Song, ${ }^{1}$ GunHa Park, ${ }^{1}$ Hyung Jik Kim, ${ }^{1}$ \\ Sung Gyun Kim ${ }^{1,2}$
}

To cite: Kim J-K, Song YR, Park GH, et al. Impact of rapid ultrafiltration rate on changes in the echocardiographic left atrial volume index in patients undergoing haemodialysis: a longitudinal observational study. BMJ Open 2017;7: e013990. doi:10.1136/ bmjopen-2016-013990

- Prepublication history and additional material is available. To view please visit the journal (http://dx.doi.org/ 10.1136/bmjopen-2016013990).

Received 24 August 2016 Revised 15 November 2016 Accepted 3 January 2017

CrossMark

\begin{abstract}
${ }^{1}$ Department of Internal Medicine and Kidney Research Institute, Hallym University Sacred Heart Hospital, Anyang, Korea ${ }^{2}$ Department of Clinical Immunology, Hallym University Sacred Heart Hospital, Anyang, Korea
\end{abstract}

Correspondence to Professor Sung Gyun Kim; imnksk@gmail.com

\section{ABSTRACT}

Objective: Optimal fluid management is essential when caring for a patient on haemodialysis (HD). However, if the fluid removal is too rapid, the resultant higher ultrafiltration rate (UFR) disadvantageously promotes haemodynamic instability and cardiac injury. We evaluated the effects of a rapid UFR on changes in the echocardiographic left atrial volume index (LAVI) over a period of time.

Design: Longitudinal observational study.

Setting and participants: A total of 124 new patients on HD.

Interventions: Echocardiography was performed at baseline and repeated after 19.7 months (range 11.323.1 months). Changes in LAVI ( $\Delta$ LAVI/year, $\mathrm{mL} / \mathrm{m}^{2}$ / year) were calculated. The UFR was expressed in $\mathrm{mL} /$ hour $/ \mathrm{kg}$, and we used the mean UFR over 30 days ( 12-13 treatments).

Main outcome measures: The 75th centile of the $\Delta \mathrm{LAVI} /$ year distribution was regarded as a 'pathological' increment.

Results: The mean interdialytic weight gain was 1.73 $\pm 0.94 \mathrm{~kg}$, and the UFR was $8.01 \pm 3.87 \mathrm{~mL} / \mathrm{hour} / \mathrm{kg}$. The significant pathological increment point in $\Delta \mathrm{LAVI} / \mathrm{year}$ was $4.89 \mathrm{~mL} / \mathrm{m}^{2} /$ year. Correlation analysis showed that $\Delta \mathrm{LAVI} /$ year was closely related to the baseline blood pressure, haemoglobin level, residual renal function and UFR. According to the receiver operating characteristics curve, the 'best' cut-off value of UFR for predicting the pathological increment was $10 \mathrm{~mL} / \mathrm{hour} / \mathrm{kg}$, with an area under the curve of 0.712 . In multivariate analysis, systolic blood pressure, a history of coronary artery disease, haemoglobin $<10 \mathrm{~g} / \mathrm{dL}$ and high UFR were significant predictors. An increase of $1 \mathrm{~mL} / \mathrm{hour} / \mathrm{kg}$ in the UFR was associated with a $22 \%$ higher risk of a worsening LAVI (OR 1.22, $95 \% \mathrm{Cl} 1.05$ to 1.41 ).

Conclusions: An increased haemodynamic load could affect left atrial remodelling in incident patients on HD. Thus, close monitoring and optimal control of UFR are needed.

\section{Strengths and limitations of this study}

- This study included newly started incident haemodialysis (HD) patients, not maintenance HD patients, to avoid the effect of dialysisassociated factors on changes in the echocardiographic left atrial volume index ( $\Delta \mathrm{LAVI} / \mathrm{year}$ ).

- We used the mean value of ultrafiltration rate from several HD sessions ( 12-13 treatments), rather than a single value.

- To minimise the effect of hypervolaemia on changes in left atrial volume index, we performed a bioimpedance test and evaluated volume status at the time of follow-up echocardiography. However, at the time of initial echocardiography, volume status was only assessed clinically.

- This is a single-centre study with a relatively small number of patients.

\section{INTRODUCTION}

Cardiovascular (CV) risk identification using Doppler echocardiography is now a recommended strategy for providing optimal management of patients starting haemodialysis (HD). ${ }^{1}$ In addition to baseline echocardiographic parameters such as the presence of left ventricular hypertrophy (LVH), an increased left ventricular mass index (LVMI) and left atrial volume index (LAVI),${ }^{2-4}$ serial monitoring of these echocardiographic measurements can offer additional prognostic information beyond that given by single values. ${ }^{5}$ Foley $e t a l^{7}$ demonstrated that the regression of left ventricular (LV) abnormalities with dialysis was associated with improved CV outcomes. Intensive treatment of risk factors for LVH produces a regression in LVMI and reduces all-cause and CV mortality. $^{2}$ Similar to the prognostic implications 
of LV changes, Tripepi $e t a l^{8}$ also showed that worsening of LAVI over a period was an independent predictor of adverse CV outcomes. Indeed, the prognostic power of changes in LAVI is of a degree that is comparable to that of LVMI. Since LAVI is commonly increased at the start of dialysis because of chronic volume overload and $\mathrm{LVH}^{9}{ }^{9}{ }^{10}$ maintaining a euvolaemic state is paramount in halting the increase in LAVI in patients on HD.

However, too rapid fluid removal to avoid hypervolaemia often results in intradialytic hypotension. ${ }^{11}{ }^{12}$ Moreover, the resultant higher ultrafiltration rate (UFR; the rate at which fluid is removed during the course of dialysis) disadvantageously promotes haemodynamic instability, tissue ischaemia and maladaptive cardiac structural changes. ${ }^{13}$ Several observational studies have found a close association between a higher UFR and adverse CV outcomes, emphasising the need to limit the maximum UFR to $<10-11 \mathrm{~mL} /$ hour $/ \mathrm{kg} .{ }^{14-17}$ However, the effects of a higher UFR on changes of echocardiographic parameters have not yet been clearly demonstrated.

We hypothesised that a higher UFR may be associated with greater LAVI increments, which, in turn, would drive all-cause and CV mortality in patients starting maintenance HD. Also, we tried to determine the optimal UFR threshold that would not cause maladaptive cardiac structural changes.

\section{METHODS}

\section{Study population}

The study was conducted at Hallym University Sacred Heart Hospital, Anyang, Korea. All incident patients on HD between January 2010 and June 2014 were asked to participate in this study. Inclusion criteria were age $\geq 18$ years and clinical stability (defined as no need for hospitalisation or emergency care within 3 months before the inclusion). Exclusion criteria were clinical instability, dialysis for acute kidney injury, active infection, life expectancy $<6$ months due to major comorbid conditions, history of significant valvular disease, history of established congestive heart failure, history of atrial fibrillation, inability to understand the study or rejection of personal data records and processing and appropriate acoustic windows for echocardiography. All procedures were performed according to the Helsinki Declaration and its revisions. All patients gave written informed consent for participation in the study and data processing. This study obtained approval from the Institutional Review Board/Ethics Committee of Hallym University Sacred Heart Hospital.

Of 275 consecutive patients, 34 were excluded because of active infection at the start of HD $(n=8)$, malignancy $(n=9)$, decompensated liver cirrhosis $(n=2)$ and other reasons $(n=15)$. Therefore, 241 patients underwent baseline echocardiography, as recommended by the Kidney Disease Outcomes Quality Initiative (KDOQI) guidelines. To minimise the effect of volume overload, we tried to perform two dimensional echocardiography when the patients became euvolaemic (ie, no pulmonary oedema or pleural effusion on chest X-ray and no peripheral pitting oedema on physical examination). We planned to perform the first echocardiography within 1 month after the start of HD, and the actual mean duration between the first HD session and the first echocardiography was $14.5 \pm 7.6$ days

Baseline demographic and clinical data were obtained, including age, gender, smoking status, underlying cause of renal disease, comorbidities (diabetes, hypertension, coronary artery disease (CAD), peripheral arterial disease and cerebrovascular accidents) and medication history. At the start of dialysis, haemoglobin, serum albumin, total cholesterol, high-density lipoprotein cholesterol, low-density lipoprotein cholesterol, triglycerides, calcium, phosphate, high sensitivity $\mathrm{C}$ reactive protein (hs-CRP) and parathyroid hormone concentrations were measured. All patients underwent regular HD for 3.54 hours, three time a week with standard bicarbonate dialysis (sodium $138 \mathrm{mmol} / \mathrm{L}, \mathrm{HCO}_{3} 35-40 \mathrm{mmol} / \mathrm{L}$, potassium $1.5 \mathrm{mmol} / \mathrm{L}$, calcium $1.25-1.5 \mathrm{mmol} / \mathrm{L}$, magnesium $0.75 \mathrm{mmol} / \mathrm{L}$ ) and semisynthetic membranes (dialysis filters surface area $1.5-1.8 \mathrm{~m}^{2}$ ). Body mass index (BMI) was calculated as the dry body weight (BW) $/(\text { height } / 100)^{2}$, with the dry BW determined once the patients became apparently euvolaemic and showed no sign of systemic volume overload. Residual renal function (RRF) was calculated as the mean of the sum of the 24-hour urea and creatinine clearance.

\section{Ultrafiltration rate}

Following routine clinical HD practice, the ultrafiltration volume was calculated as the change in BW over the course of dialysis (ie, predialysis BW-postdialysis BW). The UFR was expressed in $\mathrm{mL} / \mathrm{hour} / \mathrm{kg}$ by dividing the ultrafiltration volume by the dialysis session duration and target dry BW. In this study, we used the mean UFR over 30 days ( 12-13 treatments).

\section{Echocardiographic data}

Comprehensive echocardiographic images were performed using an ultrasound echocardiographic system (Vivid 7, GE-Vingmed, Horten, Norway) with a $2.5 \mathrm{MHz}$ probe by a single experienced cardiologist blinded to the patients' clinical information. LV ejection fraction (LVEF), LV end-diastolic volume (LVEDV) and LV endsystolic volume were calculated using biplane Simpson's methods at apical two-chamber and four-chamber views and indexed to the body surface area (BSA). The LV mass was estimated according to Devereux's formula and normalised to height to obtain the LVMI (LVM/ hour $\left.^{2.7}\right) .{ }^{18}$ Echocardiographic evidence of LVH was defined according to the recommendations of the American Society of Echocardiography. ${ }^{18}$ The left atrial (LA) volume was measured by the biplane area length method in the apical four-chamber and two-chamber views, and indexed to the BSA. ${ }^{19}$ The mitral inflow velocity was assessed by placing the pulse Doppler sample 
volume at the tips of the mitral valve leaflet. From the mitral inflow velocity curve, peak $\mathrm{E}$ velocity, its deceleration time (DT), peak A velocity and E/A ratio were assessed. In addition, tissue Doppler imaging of the mitral annulus was obtained from the apical fourchamber view using a 1-2 $\mathrm{mm}$ sample volume placed sequentially at the septal and then the lateral mitral annulus. The peak early $\left(\mathrm{E}^{\prime}\right)$ and late $\left(\mathrm{A}^{\prime}\right)$ diastolic annular velocities and $\mathrm{E} / \mathrm{A}$ ratio were assessed. The $\mathrm{E} / \mathrm{E}$ ' ratio was also measured. All reported echocardiographic measurements were the average of three to five consecutive cardiac cycles.

\section{Follow-up}

Patients who underwent baseline echocardiography were scheduled for repeat follow-up echocardiography within 12-24 months. However, 117 patients were excluded because of systolic LV dysfunction at baseline (LVEF $\leq 35 \%, \mathrm{n}=36$ ), moderate or severe valvular heart disease at baseline $(n=5)$, death or adverse $\mathrm{CV}$ events within 1 year $(n=21)$, kidney transplantation $(n=8)$, changed dialysis modality to peritoneal dialysis $(n=4)$, transfer to another dialysis unit $(\mathrm{n}=15)$, volume overload state/ cannot meet the individual's dry BW $(\mathrm{n}=10)$, session duration $<3.5$ hours $(n=5)$ and other reasons $(n=13)$. Ultimately, 124 patients underwent follow-up echocardiography. To exclude the possibility of volume overload at the time of follow-up echocardiography, we performed a bioimpedance test to measure volume status, using a portable whole-body bioimpedance spectroscopy device (Body Composition Monitor (BCM), Fresenius Medical Care, Bad Homburg, Germany), to obtain objective indicators of volume status, including estimates of overhydration $(\mathrm{OH})$, extracellular fluid (ECF)/total body water (TBW) and ECF/intracellular fluid (ICF). In fact, volume overload can be a potential source of bias when estimating LAVI. According to previously published results, $\mathrm{OH}>+2.5 \mathrm{~L}$ is regarded as an overhydrated status; thus, for patients with $\mathrm{OH}>+2$. $5 \mathrm{~L}$, we re-estimated the dry $\mathrm{BW}$ and carried out vigorous volume control. ${ }^{20}{ }^{21}$ In fact, 19 patients were overhydrated at the time of follow-up (mean $\mathrm{OH} 3.1 \pm 0.5 \mathrm{~L}$ ) and, in these patients, dry BW was re-estimated.

\section{Progression of echocardiographic LAVI and end points}

Changes in LAVI per year ( $\triangle \mathrm{LAVI} /$ year, $\mathrm{mL} / \mathrm{m}^{2} /$ year $)$ were quantified by subtracting the baseline LAVI from the LAVI obtained at follow-up, and by factoring in the time interval (years) between the two studies. We also examined the prognostic significance of the change in LAVI on the long-term outcome to verify our data with other previous studies. Adverse CV events (echocardiographic documented angina episodes, myocardial infarction, heart failure, arrhythmia, transient ischaemic attacks, stroke and other thrombotic events) and death were recorded during the follow-up. Medical information was also collected, including cause of death. We excluded patients who were transferred to other clinics, because we could not know the exact information regarding adverse $\mathrm{CV}$ events or death. Since $\Delta \mathrm{LAVI} /$ year over the 75th centile was closely associated with all-cause mortality in our study, the 75th centile of the $\Delta \mathrm{LAVI} /$ year distribution was regarded as a 'pathological' increment of LAVI over time.

\section{Statistical analysis}

Statistical analyses were performed using SPSS V.25.0 software (SPSS, Illinois, USA). All data are expressed as mean \pm SD or medians and ranges. Kolmogorov-Smirnov tests were used to analyse the normality of the distribution, and natural $\log$ values were used for skewed data. Pearson's correlation analysis was used to clarify the relationship between UFR, $\Delta \mathrm{LAVI} /$ year and various clinical and echocardiographic parameters. Multiple logistic regression analysis was performed to evaluate the determinants of the pathological increment of $\Delta \mathrm{LAVI} /$ year. A receiver operating characteristics (ROC) curve was constructed to evaluate the relationship between UFR and the pathological increment of $\Delta \mathrm{LAVI} /$ year over the period, and the area under the curve (AUC) was calculated. Statistical significance was set at $\mathrm{p}<0.05$.

\section{RESULTS}

Of the 275 consecutive patients, 34 were excluded because of active infection at the start of HD $(n=8)$, malignancy $(n=9)$, decompensated liver cirrhosis $(n=2)$ and other reasons $(\mathrm{n}=15)$. Therefore, 241 patients underwent baseline echocardiography. Table 1 summarises the baseline characteristics of the study participants. The mean age was $63.7 \pm 14.2$ years, 74 (59.7\%) were male, and the prevalence of diabetes was $60.5 \%$ $(n=75)$. At the start of dialysis, the prevalence of $\mathrm{LVH}$ was $56.5 \%$, and the mean LVEF and LAVI were 60.6 $\pm 8.3 \%$ and $48.0 \pm 19.4 \mathrm{~mL} / \mathrm{m}^{2}$, respectively. Figure 1 (left) shows the distribution of LAVI at baseline. The RRF was $6.66 \pm 2.27 \mathrm{~mL} / \mathrm{min} / 1.73 \mathrm{~m}^{2}$, and the mean UFR during the first month of HD was $8.01 \mathrm{~mL} / \mathrm{hour} / \mathrm{kg}, \sim 1.7$ $1.8 \mathrm{~kg}$ interdialytic weight gain (IDWG) per HD session.

\section{Follow-up and echocardiographic changes in LAVI}

The second echocardiographic study was repeated 19.7 (11.3-23.1) months apart, and the overall duration of follow-up was $45.7 \pm 22.0$ months. There were 17 (13.7\%) deaths ( 7 fatal CV events, 9 infections and 1 gastrointestinal bleeding event). At the second echocardiography, the urea clearance was adequate (mean $\mathrm{Kt} / \mathrm{V} 1.28$ $\pm 0.23)$, and all of the patients were euvolaemic. The mean $\mathrm{OH}, \mathrm{ECF} / \mathrm{TBW}$ and ICF/ECF were $0.18 \pm 1.15,0.46$ \pm 0.04 and $0.84 \pm 0.12$, respectively.

The mean follow-up LAVI was $48.1 \pm 19.2 \mathrm{~mL} / \mathrm{m}^{2}$, and its distribution is shown in figure 1 (middle). As this shows, although the distribution of LAVI changed slightly over time, the median value of $\triangle \mathrm{LAVI} /$ year was 0 (-5.96 to 4.89), suggesting no significant changes in LAVI during the first 1-2 years of HD (figure 1, right). 
Table 1 Baseline demographic, clinical, biochemical and echocardiographic data of the included patients according to changes in left atrial volume index/year during the study period

\begin{tabular}{|c|c|c|c|c|}
\hline & \multirow[b]{2}{*}{ Total $(n=124)$} & \multicolumn{2}{|l|}{$\Delta \mathrm{LAVI}\left(\mathrm{mL} / \mathrm{m}^{2} /\right.$ year) } & \multirow[b]{2}{*}{ p Value } \\
\hline & & $<75$ th centile $(n=91)$ & $\geq 75$ th centile $(n=33)$ & \\
\hline Age (years) & $63.7 \pm 14.2$ & $62.8 \pm 13.8$ & $65.0 \pm 12.2$ & 0.422 \\
\hline Gender, male, n (\%) & $74(59.7)$ & $35(38.5)$ & $15(45.5)$ & 0.309 \\
\hline Systolic BP (mm Hg) & $142.4 \pm 19.3$ & $139.8 \pm 19.5$ & $148.4 \pm 19.8$ & 0.033 \\
\hline Diastolic BP (mm Hg) & $80.0 \pm 9.2$ & $78.8 \pm 8.5$ & $82.4 \pm 10.4$ & 0.065 \\
\hline $\operatorname{BMI}\left(\mathrm{kg} / \mathrm{m}^{2}\right)$ & $23.0 \pm 3.5$ & $22.8 \pm 3.5$ & $23.5 \pm 3.0$ & 0.547 \\
\hline History of CAD disease, $n(\%)$ & $20(16.1)$ & $10(11.0)$ & $10(30.3)$ & 0.063 \\
\hline Diabetes & $75(60.5)$ & $52(57.1)$ & $23(69.7)$ & 0.145 \\
\hline Atrial fibrillation & $7(5.6)$ & $6(6.6)$ & $1(3.0)$ & 0.400 \\
\hline \multicolumn{5}{|l|}{ Laboratory parameters } \\
\hline Haemoglobin (g/dL) & $9.25 \pm 1.53$ & $9.33 \pm 1.51$ & $9.03 \pm 1.59$ & 0.324 \\
\hline Blood urea nitrogen (mg/dL) & $83.3 \pm 29.9$ & $85.4 \pm 31.6$ & $77.7 \pm 24.1$ & 0.199 \\
\hline Creatinine $(\mathrm{mg} / \mathrm{dL})$ & $8.07 \pm 3.64$ & $8.27 \pm 3.61$ & $7.51 \pm 3.32$ & 0.306 \\
\hline Calcium (mg/dL) & $8.14 \pm 0.89$ & $8.10 \pm 0.93$ & $8.25 \pm 0.81$ & 0.434 \\
\hline Phosphorus (mg/dL) & $5.09 \pm 1.60$ & $5.10 \pm 1.59$ & $5.06 \pm 1.69$ & 0.923 \\
\hline Uric acid (mg/dL) & $7.65 \pm 2.56$ & $7.80 \pm 2.67$ & $7.14 \pm 2.26$ & 0.237 \\
\hline Albumin (g/dL) & $3.60 \pm 0.51$ & $3.57 \pm 0.52$ & $3.63 \pm 0.51$ & 0.609 \\
\hline Total cholesterol (mg/dL) & $153.4 \pm 37.9$ & $156.1 \pm 41.2$ & $146.0 \pm 25.7$ & 0.214 \\
\hline \multicolumn{5}{|l|}{ Echocardiographic parameters } \\
\hline LVEF (\%) & $60.6 \pm 8.3$ & $60.3 \pm 8.2$ & $61.4 \pm 8.7$ & 0.532 \\
\hline LAVI $\left(\mathrm{mL} / \mathrm{m}^{2}\right)$ & $48.0 \pm 19.4$ & $50.1 \pm 19.6$ & $44.3 \pm 16.5$ & 0.068 \\
\hline LVEDVI & $61.8 \pm 17.5$ & $61.9 \pm 15.6$ & $61.5 \pm 17.5$ & 0.923 \\
\hline LVMI & $115.4 \pm 33.7$ & $112.6 \pm 29.7$ & $122.4 \pm 44.5$ & 0.183 \\
\hline LVH & $70(56.5)$ & $50(54.9)$ & $20(60.6)$ & 0.362 \\
\hline Concentric & 45 (36.3) & $33(36.3)$ & $12(36.4)$ & 0.564 \\
\hline Eccentric & $25(20.2)$ & $17(18.7)$ & $8(24.2)$ & 0.327 \\
\hline E/A ratio & $0.77 \pm 0.38$ & $0.84 \pm 0.46$ & $0.63 \pm 0.21$ & 0.586 \\
\hline$E / E^{\prime}$ ratio & $12.9 \pm 6.2$ & $13.2 \pm 5.3$ & $12.3 \pm 5.0$ & 0.391 \\
\hline \multicolumn{5}{|l|}{ Dialysis-related parameters } \\
\hline IDWG (kg) & $1.73 \pm 0.94$ & $1.62 \pm 0.85$ & $2.37 \pm 1.06$ & 0.001 \\
\hline Ultrafiltration rate $(\mathrm{mL} / \mathrm{kg} / \mathrm{hour})$ & $8.01 \pm 3.87$ & $7.28 \pm 3.51$ & $10.1 \pm 4.13$ & $<0.001$ \\
\hline Residual renal function & $6.66 \pm 2.27$ & $6.48 \pm 2.32$ & $7.57 \pm 1.90$ & 0.218 \\
\hline Urine volume $(\mathrm{mL} / \text { day })^{*}$ & $1000(100-2450)$ & $1000(100-2750)$ & $1000(100-2140)$ & 0.965 \\
\hline
\end{tabular}

All data are expressed as means \pm SD except for those with * ${ }^{*}$ which are expressed as medians with ranges.

$\mathrm{BP}$, blood pressure; BMI, body mass index; CAD, coronary artery disease; LAVI, left atrial volume index; LVEDVI, left ventricular end-diastolic volume index; LVEF, left ventricular ejection fraction; LVMI, left ventricular mass index; LVH, left ventricular hypertrophy; IDWG, interdialytic weight gain.

However, when the $\triangle \mathrm{LAVI} /$ year was divided into quartiles, worsening of the LAVI above the 75th centile $\left(\geq 4.89 \mathrm{~mL} / \mathrm{m}^{2} /\right.$ year $)$ was closely associated with an increased risk of all-cause mortality (see online supplementary figure S1). Therefore, in this study, an increase in $\Delta \mathrm{LAVI} /$ year over the 75 th centile was regarded as a pathological increment.

\section{Predictors of increased $\Delta \mathrm{LAVI} / \mathrm{year}$ over time}

Interestingly, of the baseline demographic, laboratory and echocardiographic parameters that might distinguish patients with versus without a pathological increment in $\triangle \mathrm{LAVI} /$ year, only a significantly higher systolic blood pressure (BP) at baseline was relevant. Differences in diastolic BP, history of CAD and baseline LAVI were marginally significant (table 1 ). However, there were definite differences in IDWG and UFR between the two groups. Patients with a significant worsening of the
$\Delta \mathrm{LAVI} /$ year had a considerably higher UFR than did those without $(10.1 \pm 4.13$ vs $7.28 \pm 3.51 \mathrm{~mL} /$ hour $/ \mathrm{kg})$. The ROC curve analysis revealed a strong relationship between UFR and the pathological increment in $\triangle \mathrm{LAVI} /$ year. With a UFR cut-off value of $10 \mathrm{~mL} /$ hour $/ \mathrm{kg}$, the area under the ROC curve was 0.712 , and the sensitivity and specificity were 0.71 and 0.68 , respectively (figure 2, left). In a fully adjusted model, the area increased to 0.856 (figure 2, right). Correlation analysis showed that baseline LAVI levels were closely associated with age, BP, haemoglobin and echocardiographic parameters such as baseline LVEDV index (LVEDVI), LVMI, LVH and E/E' ratio. In contrast, $\triangle \mathrm{LAVI} /$ year was related only to $\mathrm{BP}$, haemoglobin value, RRF and UFR. None of the baseline echocardiographic parameters were related to the changes in $\triangle \mathrm{LAVI} /$ year (table 2).

Table 3 shows significant predictors of a pathological increment in $\Delta \mathrm{LAVI} /$ year over time in patients on $\mathrm{HD}$. 

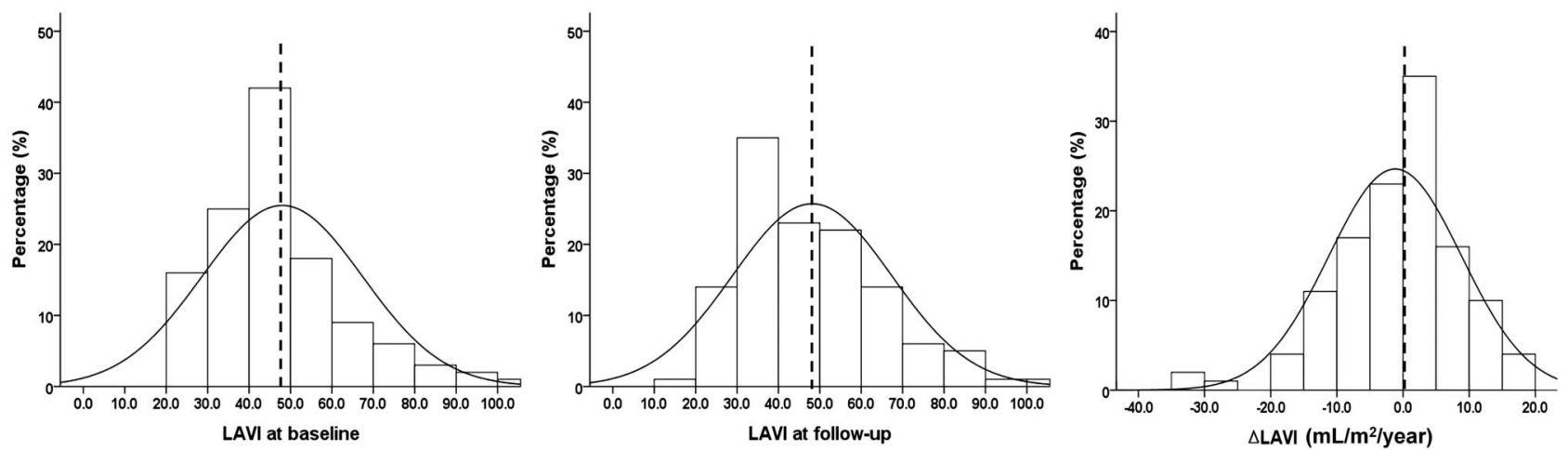

Figure 1 Distribution of baseline and follow-up left atrial volume index ( $\mathrm{AVI})$ and $\triangle \mathrm{LAVI}$ over time. During the first 2 years after beginning haemodialysis, no definite changes in LAVI occurred.
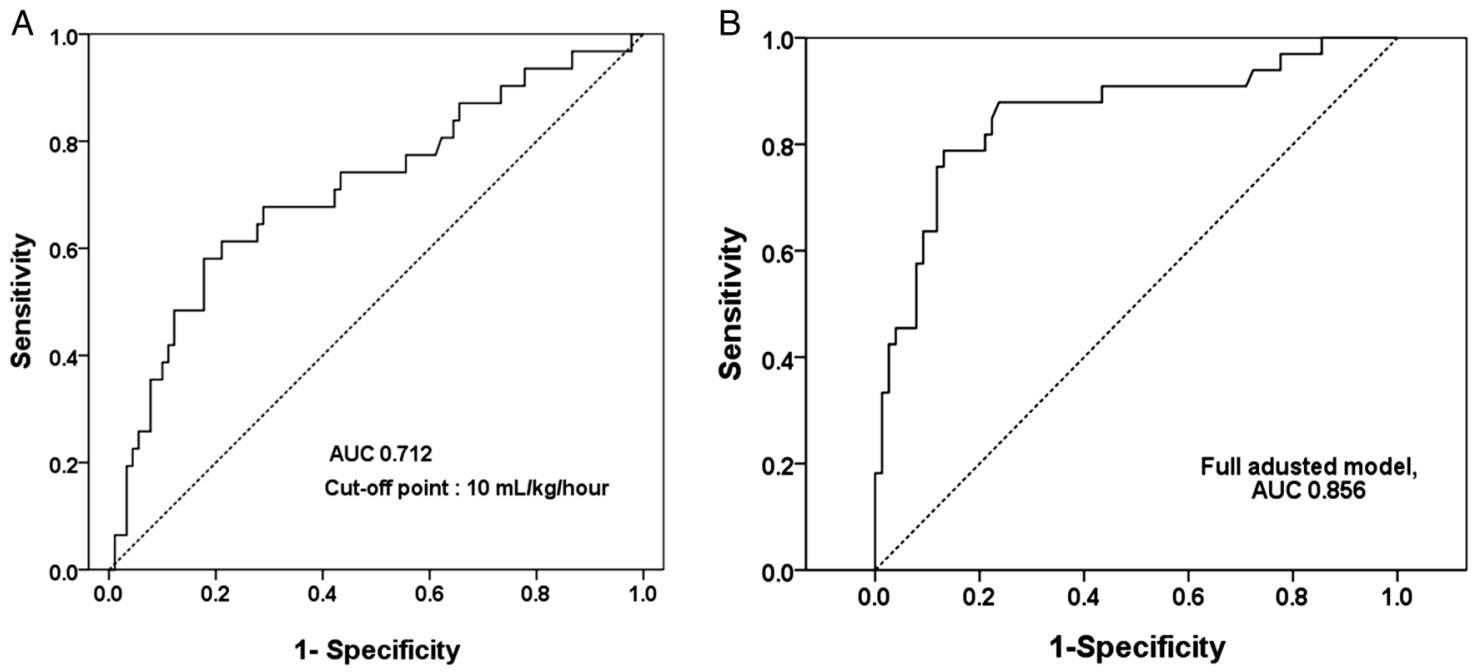

Figure 2 Receiver operating characteristics curves for ultrafiltration rate (UFR) for predicting the pathological increment of $\Delta \mathrm{LAVl} /$ year. The best cut-off value of UFR for predicting the pathological increment was $10 \mathrm{~mL} / \mathrm{hour} / \mathrm{kg}$, with an area under the curve of 0.712 .

In the univariate analyses, an increased systolic BP, history of $\mathrm{CAD}$, haemoglobin $<10 \mathrm{~g} / \mathrm{dL}$ and high UFR were closely associated with the increment. In the multivariate analysis, haemoglobin $<10 \mathrm{~g} / \mathrm{dL}$ (OR 6.15, 95\% CI 2.01 to 35.79; $\mathrm{p}=0.006$ ), previous $\mathrm{CAD}$ disease (OR $3.49,95 \%$ CI 1.32 to 20.43 ; $\mathrm{p}=0.039$ ) and increased UFR (OR 1.22, 95\% CI 1.05 to $1.41 ; \mathrm{p}=0.009$ ) were significant determinants. When the UFR was replaced by UFR $>10 \mathrm{~mL} /$ hour $/ \mathrm{kg}$, the prognostic effect of UFR strengthened considerably (OR 8.54, 95\% CI 1.68 to 21.29; $\mathrm{p}=0.010$ ).

\section{DISCUSSION}

In this study, (1) we confirmed the prognostic significance of LAVI monitoring-a worsening of $\triangle \mathrm{LAVI}$ over $\sim 5 \mathrm{~mL} / \mathrm{m}^{2} /$ year was closely associated with long-term mortality; (2) increased BP, history of CAD, anaemia and higher UFR were significant predictors of the pathological increment in $\triangle \mathrm{LAVI} /$ year; and (3) using a cut-off level of $10 \mathrm{~mL} / \mathrm{hour} / \mathrm{kg}$, a higher UFR strongly affected the maladaptive LAVI structural changes. With these results, avoiding too rapid fluid removal could be suggested as a useful therapeutic option to prevent the progression of cardiomyopathy in patients on HD.

Cardiac risk identification using two dimensional echocardiography is recommended for the management of new patients on HD. In addition to the baseline work-up, serial echocardiography monitoring could provide prognostic information beyond that given by single studies. LA size has proven to be a powerful predictor of outcome in numerous diseases, including myocardial infarction and heart failure. ${ }^{22-24}$ Additionally, a worsening in LAVI over time could also be a valuable predictor of adverse $\mathrm{CV}$ outcomes beyond the significance of the baseline LAVI. ${ }^{8}$ Tripepi et $a l^{\beta}$ demonstrated that an increased LAVI predicted incident CV events, independent of LVMI. However, clinical factors predicting a worsening of the LAVI over time have not been identified. In general, the LA enlarges in response to pressure and volume overload. ${ }^{9}$ Since most patients with advanced renal impairment 
Table 2 Correlation between markers of $\triangle \mathrm{LAVI} /$ year, ultrafiltration rate and various biochemical parameters

\begin{tabular}{|c|c|c|c|c|c|c|}
\hline & \multicolumn{2}{|c|}{ Baseline LAVI, mL/m² } & \multicolumn{2}{|c|}{$\Delta \mathrm{LAVI} /$ year, $\mathrm{mL} / \mathrm{m}^{2} /$ year } & \multicolumn{2}{|c|}{ UFR, mL/kg/hour } \\
\hline & $r$ & p Value & $\mathbf{r}$ & p Value & $r$ & p Value \\
\hline Age & 0.180 & 0.042 & 0.111 & 0.219 & -0.247 & 0.006 \\
\hline Gender (male) & 0.038 & 0.678 & 0.090 & 0.319 & 0.160 & 0.080 \\
\hline Diabetic, n (\%) & -0.032 & 0.726 & 0.111 & 0.221 & 0.122 & 0.182 \\
\hline Systolic BP (mm Hg) & 0.183 & 0.043 & 0.247 & 0.010 & 0.276 & 0.004 \\
\hline Haemoglobin & -0.193 & 0.039 & 0.210 & 0.024 & -0.032 & 0.732 \\
\hline BMI & -0.129 & 0.154 & -0.009 & 0.920 & -0.182 & 0.046 \\
\hline Baseline EF (\%) & -0.122 & 0.177 & 0.165 & 0.067 & 0.137 & 0.135 \\
\hline Baseline LVEDVI & 0.348 & $<0.001$ & -0.096 & 0.348 & 0.140 & 0.180 \\
\hline Baseline LVMI & 0.499 & $<0.001$ & -0.009 & 0.924 & 0.161 & 0.096 \\
\hline Baseline LVH & 0.430 & $<0.001$ & -0.147 & 0.104 & 0.173 & 0.058 \\
\hline Baseline E/A ratio & 0.395 & 0.439 & -0.488 & 0.326 & 0.388 & 0.612 \\
\hline Baseline $E / E^{\prime}$ ratio & 0.382 & $<0.001$ & -0.087 & 0.359 & -0.009 & 0.919 \\
\hline$\Delta \mathrm{EF}(\%)$ & 0.070 & 0.440 & -0.154 & 0.088 & -0.016 & 0.863 \\
\hline$\triangle$ LVEDVI & -0.194 & 0.062 & 0.495 & $<0.001$ & 0.184 & 0.083 \\
\hline$\Delta \mathrm{LAVI}$ & - & - & - & - & 0.228 & 0.012 \\
\hline$\Delta$ LVMI & -0.129 & 0.195 & 0.287 & 0.003 & 0.076 & 0.455 \\
\hline$\Delta E / E^{\prime}$ ratio & -0.195 & 0.039 & 0.328 & $<0.001$ & 0.090 & 0.351 \\
\hline $\mathrm{spKt} / \mathrm{V}$ & 0.412 & 0.441 & 0.020 & 0.680 & 0.370 & 0.601 \\
\hline RRF & 0.085 & 0.359 & -0.184 & 0.045 & -0.216 & 0.020 \\
\hline Urine volume & -0.048 & 0.632 & -0.032 & 0.753 & -0.238 & 0.018 \\
\hline IDWG (kg) & 0.078 & 0.397 & 0.168 & 0.062 & 0.859 & $<0.001$ \\
\hline UFR (mL/kg/hour) & 0.114 & 0.213 & 0.228 & 0.012 & - & - \\
\hline
\end{tabular}

Table 3 Variables associated with a pathological increment of $\Delta \mathrm{LAVI}$ over a period ( $\Delta \mathrm{LAVI} /$ year $>75$ th centile)

\begin{tabular}{|c|c|c|c|c|c|}
\hline \multirow[b]{2}{*}{ Variables } & \multirow[b]{2}{*}{ Unit } & \multicolumn{2}{|l|}{ Univariate } & \multicolumn{2}{|l|}{ Multivariate ${ }^{\star}$} \\
\hline & & OR (95\% Cl) & p Value & OR $(95 \% \mathrm{Cl})$ & p Value \\
\hline Age & $>70$ years & 1.57 (0.69 to 3.57$)$ & 0.277 & - & - \\
\hline Gender & Male vs female & 0.75 (0.33 to 1.67$)$ & 0.484 & - & - \\
\hline SBP & Per 10 mm Hg & 1.27 (1.02 to 1.59$)$ & 0.036 & 1.29 (0.96 to 1.72$)$ & 0.088 \\
\hline BMI & Per $1 \mathrm{~kg} / \mathrm{m}^{2}$ & $1.11(0.21$ to 6.01$)$ & 0.904 & - & - \\
\hline Diabetes & Presence & 1.72 (0.74 to 4.03$)$ & 0.209 & - & - \\
\hline Atrial fibrillation & Presence & 0.44 (0.05 to 3.82$)$ & 0.459 & - & - \\
\hline Haemoglobin & $<10 \mathrm{~g} / \mathrm{dL}$ & 4.51 (1.46 to 13.9$)$ & 0.009 & 6.15 (2.01 to 35.79 ) & 0.006 \\
\hline Previous CAD history & Presence & 3.52 (1.31 to 9.49$)$ & 0.013 & 3.49 (1.32 to 20.43$)$ & 0.039 \\
\hline LVH, at baseline & Presence & 1.26 (0.56 to 2.83$)$ & 0.575 & - & - \\
\hline LVMI, at baseline & Per 1 & 1.01 (0.99 to 1.02$)$ & 0.187 & - & - \\
\hline \multirow[t]{2}{*}{ UFR } & Per $1 \mathrm{~mL} / \mathrm{kg} / \mathrm{hour}$ & 1.22 (1.08 to 1.37$)$ & 0.001 & $1.22(1.05$ to 1.41$)$ & 0.009 \\
\hline & $>10 \mathrm{~mL} / \mathrm{kg} / \mathrm{hour}$ & 6.24 (2.62 to 14.86$)$ & $<0.001$ & 8.54 (1.68 to 21.29$)$ & 0.010 \\
\hline IDWG & Per $1 \mathrm{~kg}$ & 2.11 (1.33 to 3.34$)$ & 0.002 & 1.08 (0.37 to 2.06$)$ & 0.772 \\
\hline
\end{tabular}

usually have chronic volume overload and LVH, maintaining a euvolaemic state and an effort to halt further deterioration in the LAVI may be important in these patients. ${ }^{25}$

Rapid fluid removal to achieve a euvolaemic state often requires a higher UFR, which could promote haemodynamic instability, tissue ischaemia and maladaptive cardiac structural changes. Existing observational data suggest a robust association between a greater UFR and adverse CV outcomes. ${ }^{16}{ }^{17}$ The potential mechanism is as follows. Too rapid, a UFR is more likely to induce episodes of intradialytic hypotension that can be treated with fluid administration, and this could lead to myocardial stunning and persistent 
volume expansion, as well as hypertension. ${ }^{26-28}$ All of these noxious stimuli ultimately lead to adverse cardiac structural changes and chamber dysfunction, contributing to high mortality in patients on dialysis. ${ }^{13} 29$ On the basis of this background, our study verified the prognostic significance of LAVI monitoring and evaluated whether worsening of the LAVI is affected by the UFR.

Also, it has been suggested that LA volume could be a marker of the severity and duration of diastolic dysfunction, and increased LA volume size or LAVI may reflect the cumulative effect of increased filling pressures over time. Therefore, the higher UFR may cause a thickened myocardium, increased filling pressure and resultant enlargement of LAVI over a period of time. This may be an important pathophysiological link between higher UFR and worsening of LAVI. Supporting this, in this study we observed a strong correlation between $\Delta \mathrm{E} / \mathrm{E}^{\prime}$ ratio and $\triangle \mathrm{LAVI} /$ year $(\mathrm{r}=0.328, \mathrm{p}<0.001)$.

Over the median interval of 19 months between the two echocardiographic studies, the mean difference in the $\Delta \mathrm{LAVI} /$ year was 0 , suggesting that no changes in LAVI occurred with dialysis. This suggests that during the early period after beginning HD, no definite changes occurred in cardiac structure. Our findings differ from those of Tripepi $e t$ al, who observed a significant increase in LAVI at an interval of $17 \pm 2$ months. However, their study enrolled maintenance HD patients; therefore, the possible effects of dialysis duration and RRF loss on the changes in LAVI cannot be excluded. Interestingly, however, some patients showed a substantial increase in the $\Delta \mathrm{LAVI} /$ year during this period. In our study, an increase in the $\Delta \mathrm{LAVI} /$ year of $\sim 5 \mathrm{~mL} / \mathrm{m}^{2}$ / year was regarded as the pathological increment, and it was clearly associated with a significant increase in mortality. On the basis of these results, our findings support the usefulness of repeated echocardiographic monitoring of the cardiac structure, as it can provide important prognostic information.

Of the baseline demographic, clinical, laboratory and echocardiographic parameters examined, only a high BP, anaemia, CAD history and UFR were significant predictors of the pathological increment. Surprisingly, a higher UFR was a strong independent determinant of the LAVI increment. Using a cut-off point of $10 \mathrm{~mL} /$ hour $/ \mathrm{kg}$, the risk of a pathological LAVI increment was increased significantly. Similarly, Saran $e t a l^{17}$ reported an association between a UFR $>10 \mathrm{~mL} / \mathrm{hour} / \mathrm{kg}$ and higher all-cause mortality. Although several other studies have suggested that a higher UFR (ie, $12-13 \mathrm{~mL} / \mathrm{hour} / \mathrm{kg}$ ) is the best cut-off for predicting mortality, those values were based on data from Western populations. ${ }^{15}{ }^{16}$ We believe a cut-off of $10 \mathrm{~mL} /$ hour $/ \mathrm{kg}$ for the UFR is appropriate for Asian populations on $\mathrm{HD}$, and limiting the maximum UFR to $10 \mathrm{~mL} /$ hour $/ \mathrm{kg}$ may help to minimise CV risk. Since UFR is one of the few modifiable risk factors in HD care, efforts to reduce the UFR are mandatory, including reducing IDWG, extending the dialysis duration or performing more frequent HD.
Another interesting finding in our study was that higher systolic BP was a good indicator of increment of LAVI over a period in patients on HD. Supporting this, Milan $e t a l^{30}$ also found that LAVI was significantly increased in the essential hypertensive group compared with the normal population, and depended largely on BP levels. These findings emphasise the importance of $\mathrm{BP}$ control and LA evaluation in patients undergoing $\mathrm{HD}$.

A main strength of this study is that these are the only currently available data in which the harmful effect of rapid UFR was demonstrated in newly started patients on HD. Although Tripepi $e t a l^{8}$ also evaluated the prognostic value of $\triangle \mathrm{LAVI} /$ year, their first echocardiography was performed in maintenance HD patients. Therefore, dialysis-associated factors could affect the changes in $\Delta \mathrm{LAVI} /$ year, such as dialysis duration, adequacy and the accumulation of molecular toxins. Thus, our data are more applicable to $\mathrm{HD}$ patient care, because the KDOQI guidelines recommend an echocardiographic evaluation at the start of dialysis. ${ }^{1}$ Moreover, we clearly showed the volume status at the time of the second echocardiography using the BCM. Since LAVI is affected by volume status, if patients are in fluid overload, the follow-up LAVI could be interpreted mistakenly as being much higher than it actually is. Third, compared with other studies, we considered RRF, based on 24-hour urine volume, to be a strong prognostic marker of mortality. ${ }^{31}$

Important limitations in this study are that the issue was evaluated at a single centre; thus, the conclusions lack generalisability with respect to the population, ethnicity and site. Further large-scale multicentre studies including participants of various ethnicities are needed. Second, at the time of the initial echocardiography, we could not perform objective tests such as bioimpedance tests or measurements of $\mathrm{N}$-terminal pro-brain natriuretic peptide. However, we tried to perform baseline echocardiography when the patients were clinically euvolaemic, and those with a baseline LVEF $<35 \%$ were not included. Third, we could not measure certain markers of inflammation or oxidative stress, factors that possibly influence cardiac changes.

\section{CONCLUSIONS}

In patients starting HD, LAVI monitoring using echocardiography is useful for predicting prognosis, and a worsening of $\triangle \mathrm{LAVI}$ exceeding $5 \mathrm{~mL} / \mathrm{m}^{2} /$ year was closely associated with long-term mortality. A higher UFR could be a significant determinant of the pathological increment in $\Delta \mathrm{LAVI} /$ year; using a cut-off of $10 \mathrm{~mL} /$ hour $/ \mathrm{kg}$, a higher UFR strongly predicted maladaptive LAVI structural changes. Since UFR is one of the few modifiable risk factors, limiting the maximum UFR to $10 \mathrm{~mL} /$ hour $/ \mathrm{kg}$ could be a valuable treatment strategy when caring for patients on HD.

Acknowledgements The English in this document has been checked by at least two professional editors, both native speakers of English. 
Contributors J-KK is responsible for patient recruitment, explaining and obtaining informed consent, and data analysis and writing up. YRS is responsible for data analysis and writing up. GHP is responsible for patient recruitment and obtaining informed consent. HJK is responsible for data analysis and statistical advisory. SGK is responsible for patient recruitment, explaining and obtaining informed consent, and data analysis and writing up.

Funding This research was supported by Hallym University Research Fund (01-2012-04).

\section{Competing interests None declared.}

Patient consent Obtained.

Provenance and peer review Not commissioned; externally peer reviewed.

Data sharing statement No additional data are available.

Open Access This is an Open Access article distributed in accordance with the Creative Commons Attribution Non Commercial (CC BY-NC 4.0) license which permits others to distribute, remix, adapt, build upon this work noncommercially, and license their derivative works on different terms, provided the original work is properly cited and the use is non-commercial. See: http:// creativecommons.org/licenses/by-nc/4.0/

\section{REFERENCES}

1. K/DOQI Workgroup. K/DOQI clinical practice guidelines for cardiovascular disease in dialysis patients. Am J Kidney Dis 2005;45 (Suppl 3):S1-153.

2. London GM, Pannier B, Guerin AP, et al. Alterations of left ventricular hypertrophy in and survival of patients receiving hemodialysis: follow-up of an interventional study. J Am Soc Nephrol 2001;12:2759-67.

3. Kim SJ, Han SH, Park JT, et al. Left atrial volume is an independent predictor of mortality in CAPD patients. Nephrol Dial Transplant 2011;26:3732-9.

4. Zoccali C, Benedetto FA, Mallamaci F, et al. Prognostic impact of the indexation of left ventricular mass in patients undergoing dialysis. $J$ Am Soc Nephrol 2001;12:2768-74.

5. Zoccali C, Benedetto FA, Tripepi G, et al. Left ventricular systolic function monitoring in asymptomatic dialysis patients: a prospective cohort study. J Am Soc Nephrol 2006;17:1460-5.

6. Zoccali $\mathrm{C}$, Benedetto FA, Mallamaci $\mathrm{F}$, et al. Left ventricular mass monitoring in the follow-up of dialysis patients: prognostic value of left ventricular hypertrophy progression. Kidney Int 2004;65:1492-8.

7. Foley RN, Parfrey PS, Kent GM, et al. Serial change in echocardiographic parameters and cardiac failure in end-stage rena disease. J Am Soc Nephrol 2000;11:912-6.

8. Tripepi G, Benedetto FA, Mallamaci $F$, et al. Left atrial volume monitoring and cardiovascular risk in patients with end-stage renal disease: a prospective cohort study. J Am Soc Nephrol 2007; 18:1316-22.

9. Abhayaratna WP, Seward JB, Appleton CP, et al. Left atrial size: physiologic determinants and clinical applications. J Am Coll Cardiol 2006; 47:2357-63.

10. Koc M, Toprak A, Tezcan H, et al. Uncontrolled hypertension due to volume overload contributes to higher left ventricular mass index in CAPD patients. Nephrol Dial Transplant 2002;17:1661-6.

11. Weiner DE, Brunelli SM, Hunt A, et al. Improving clinical outcomes among hemodialysis patients: a proposal for a 'volume first' approach from the chief medical officers of US dialysis providers. Am J Kidney Dis 2014;64:685-95.
12. Chazot C, Wabel P, Chamney $\mathrm{P}$, et al. Importance of normohydration for the long-term survival of haemodialysis patients. Nephrol Dial Transplant 2012;27:2404-10.

13. Assimon MM, Flythe JE. Rapid ultrafiltration rates and outcomes among hemodialysis patients: re-examining the evidence base. Curr Opin Nephrol Hypertens 2015;24:525-30.

14. Agar JW. Personal viewpoint: limiting maximum ultrafiltration rate as a potential new measure of dialysis adequacy. Hemodial Int 2016;20:15-21.

15. Movilli E, Gaggia P, Zubani R, et al. Association between high ultrafiltration rates and mortality in uraemic patients on regular haemodialysis. A 5-year prospective observational multicentre study. Nephrol Dial Transplant 2007;22:3547-52

16. Flythe JE, Kimmel SE, Brunelli SM. Rapid fluid removal during dialysis is associated with cardiovascular morbidity and mortality. Kidney Int 2011;79:250-7.

17. Saran R, Bragg-Gresham JL, Levin NW, et al. Longer treatment time and slower ultrafiltration in hemodialysis: associations with reduced mortality in the DOPPS. Kidney Int 2006;69:1222-8.

18. Lang RM, Badano LP, Mor-Avi V, et al. Recommendations for cardiac chamber quantification by echocardiography in adults: an update from the American Society of Echocardiography and the European Association of Cardiovascular Imaging. J Am Soc Nephrol 2015;28:1-39.

19. Jiamsripong $P$, Honda T, Reuss CS, et al. Three methods for evaluation of left atrial volume. J Echocardiogr 2008;9:351-5.

20. Passauer J, Petrov H, Schleser A, et al. Evaluation of clinical dry weight assessment in haemodialysis patients using bioimpedance spectroscopy: a cross-sectional study. Nephrol Dial Transplant 2010;25:545-51.

21. Wizemann V, Wabel $\mathrm{P}$, Chamney $\mathrm{P}$, et al. The mortality risk of overhydration in haemodialysis patients. Nephrol Dial Transplant 2009;24:1574-9.

22. Tsang TS, Barnes ME, Gersh BJ, et al. Left atrial volume as a morphophysiologic expression of left ventricular diastolic dysfunction and relation to cardiovascular risk burden. Am J Cardiol 2002;90:1284-9.

23. Kizer JR, Bella JN, Palmieri V, et al. Left atrial diameter as an independent predictor of first clinical cardiovascular events in middle-aged and elderly adults: the Strong Heart Study (SHS). Am Heart J 2006;151:412-8.

24. Moller JE, Hillis GS, Oh JK, et al. Left atrial volume: a powerful predictor of survival after acute myocardial infarction. Circulation 2003;107:2207-12.

25. Hung SC, Kuo KL, Peng $\mathrm{CH}$, et al. Volume overload correlates with cardiovascular risk factors in patients with chronic kidney disease. Kidney Int 2014;85:703-9.

26. Burton JO, Jefferies HJ, Selby NM, et al. Hemodialysis-induced cardiac injury: determinants and associated outcomes. Clin J Am Soc Nephrol 2009;4:914-20.

27. Burton JO, Jefferies HJ, Selby NM, et al. Hemodialysis-induced repetitive myocardial injury results in global and segmental reduction in systolic cardiac function. Clin J Am Soc Nephrol 2009;4:1925-31.

28. Stefansson BV, Brunelli SM, Cabrera C, et al. Intradialytic hypotension and risk of cardiovascular disease. Clin J Am Soc Nephrol 2014;9:2124-32.

29. Jefferies HJ, Virk B, Schiller B, et al. Frequent hemodialysis schedules are associated with reduced levels of dialysis-induced cardiac injury (myocardial stunning). Clin J Am Soc Nephrol 2011;6:1326-32.

30. Milan A, Caserta MA, Dematteis A, et al. Blood pressure levels, left ventricular mass and function are correlated with left atrial volume in mild to moderate hypertensive patients. J Hum Hypertens 2009;23:743-50.

31. Vilar E, Farrington K. Emerging importance of residual renal function in end-stage renal failure. Semin Dial 2011;24:487-94. 